\section{Alpha hemoglobinophaties in Rosario, Argentina}

\author{
Mara Jorgelina Ojeda, ${ }^{1}$ \\ Susana Mabel Perez, ${ }^{1}$ \\ Arianna Flavia Pratti, ${ }^{1}$ \\ Karina Lucrecia Calvo, ${ }^{1}$ \\ Mariana Paula Raviola, ${ }^{1}$ \\ María Eda Voss, ${ }^{1}$ \\ Gladis Marcela Williams, \\ Nélida Inés Noguera, ${ }^{1}$ \\ María Magdalena Carbonell, ${ }^{1}$ \\ Mónica Teresita Aixalá, ${ }^{2}$ \\ Irma Margarita Bragós ${ }^{1}$ \\ ${ }^{1}$ Hematology Department. Faculty of \\ Biochemical and Pharmaceutical \\ Sciences. National University of Rosario, \\ Argentina; ${ }^{2}$ Laboratory Aixalá-Blanco. \\ CABA. Argentina
}

\begin{abstract}
Hemoglobinopathies are the most common recessive diseases worldwide. While the molecular basis of $\beta$-thalassemia in Rosario has been addressed, that of $\alpha$-thalassemia and $\alpha$ structural alterations, has not. In this study 105 individuals from different families referred to our center were investigated for alpha hemoglobinopathies because of low MCV ( $<85 \mathrm{fL}$ ), low $\mathrm{MCH}$ $(<27 \mathrm{dg})$, normal HbA2 $(\leq 3.5 \%)$ and transferrin saturation of $>15 \%$. Six of them with a clinical phenotype of thalassemia intermedia were diagnosed as $\mathrm{Hb} \mathrm{H}$ disease (five cases) and $\mathrm{Hb} \mathrm{H}$ like (one case). It also included one patient with sickle cell trait, confirmed by hematological and molecular studies. We were able to identify alpha globin genes mutations in 92 individuals (87.6\%): 88 patients with alpha thalassemia, 3 patients with structural alterations and one with both. In total, 13 individuals $(12.4 \%)$ had no identified $\alpha$-globin mutation. This study is the first to deal with the molecular basis of $\alpha$-hemoglobinophaties in Rosario.
\end{abstract}

\section{Introduction}

The hemoglobinopathies are a heterogeneous group of genetic disorders caused by mutations affecting the globin-chain genes. Generically, these mutations can be classified as structural alterations which result in the production of abnormal proteins or as thalassemias characterized by defective synthesis of $\alpha$ or $b$ globin chain that result in $\alpha$-thalassemia and $\beta$-thalassemia, respectively. Alpha thalassemia (thal) is probably the most common single gene disorders worldwide. ${ }^{1}$ There is strong evidence from population data that malaria selection explains the current distribution of the thalassemia. The one notable exception is South America, where in evolutionary terms malaria was introduced only relatively recently. ${ }^{2}$ The racial admixture among native Indians and African and European descendants in the population of Rosario has produced hemoglobin $(\mathrm{Hb})$ alterations which reflect the diversity of racial origins.

The current Argentinian population was formed by successive migratory waves. Amerindians already occupied Argentinian territory when the Spaniards arrived in 1500. From the $16^{\text {th }}$ to $19^{\text {th }}$ centuries Africans were brought as slaves, with other migratory waves of Europeans occurring in the $19^{\text {th }}$ and $20^{\text {th }}$ centuries, mainly from Italy and Spain. ${ }^{3}$

In our country we can also identify three moments of influx of Chinese immigrants. The first was between 1914 and 1949, the second from 1978 and in the early years of the $80 \mathrm{~s}$ and the last flow of Chinese immigrants came from 1990 to about 1999.

The relative degree to which globin chain synthesis is impaired reflects the genetic heterogeneity of $\alpha$-thal and determines the clinical phenotype. In contrast to $\beta$-thal, where point mutations predominate, deletions constitute the bulk of the molecular defects in $\alpha$-thal. ${ }^{4}$ Four clinical conditions of increased severity are recognized: two carrier states (i.e., $\alpha^{+}$-thal usually caused by the deletion or dysfunction of one of the four normal $\alpha$ globin genes and $\alpha^{\circ}$ thal resulting from deletion or dysfunction of two $\alpha$ genes) and two clinically relevant forms [i.e., $\mathrm{Hb} \mathrm{H}$ disease (only one functioning $\alpha$ gene) and Hb Bart's hydrops fetalis syndrome (no functioning $\alpha$ genes)]. The diagnosis of the first two phenotypes is not as straightforward as that of $\beta$-thal carrier states and requires molecular studies for confirmation. ${ }^{5}$ Advances in molecular characterization of the $\alpha$-globin gene cluster have clarified the genetic basis of these phenotypes. While the molecular basis of $\beta$-thal in Rosario has been addressed ${ }^{6}$ that of $\alpha$ thal and $\alpha$ structural alterations has not. This study is the first to deal with the molecular basis of $\alpha$-hemoglobinophaties in Rosario.

\section{Materials and Methods}

In this study 105 individuals from different families of different ethnic origins referred to our center were investigated for $\alpha$ hemoglobinopathies because of low MCV
Correspondence: Irma Margarita Bragós, Hematology Department. Faculty of Biochemical and Pharmaceutical Sciences. National University of Rosario, Argentina. Tel.: 54.341.4804592/3.

E-mail: imbragos@yahoo.com.ar

Key words: Hemoglobinopathies; alpha thalassemia; microcytic hypocromic anemia.

Contributions: IMB, MJO, conception and design; IMB, SMP, MJO, MPR, NIN, AFP, development of methodology; IMB, MMC, GMW, MEV, NIN, MPR, MTA, acquisition of data; IMB, SMP, MJO, KLC, MTA, AFP, analysis and interpretation of data; IMB, SMP, MJO, KLC, writing, review and/or revision of the manuscript; IMB, KLC, AFP, MMC, GMW, MEV, administrative, technical, or material support; IMB, SMP, MJO, study supervision.

Conflict of interest: the authors declare no potential conflict of interest.

Received for publication: 11 October 2016. Revision received: 1 December 2016.

Accepted for publication: 27 December 2016

This work is licensed under a Creative Commons Attribution 4.0 License (by-nc 4.0).

(C) Copyright M.J. Ojeda et al., 2017

Licensee PAGEPress, Italy

Thalassemia Reports 2017; 7:5655

doi:10.4081/thal.2017.5655

( $<85 \mathrm{fL}$ ), low $\mathrm{MCH}(<27 \mathrm{dg})$, normal $\mathrm{HbA}_{2}$ $(\leq 3.5 \%)$ and transferrin saturation of $>15 \%$. Six of them with a clinical phenotype of thalassemia intermedia were diagnosed as $\mathrm{Hb} \mathrm{H}$ disease (five cases) and $\mathrm{Hb} \mathrm{H}$ like (one case). It also included one patient with sickle cell trait, confirmed by hematological and molecular studies. The study was approved by the ethical committee at the Facultad de Ciencias Bioquímicas y Farmacéuticas, Universidad Nacional de Rosario and informed consent was obtained from all enrollees.

Blood counts were determined using a hematology analyzer (Beckman-Coulter, Fullerton, CA, USA). Cellulose acetate electrophoresis ( $\mathrm{pH}$ 8.6) was carried out using standard methods and the $\mathrm{Hb}_{2}$ and $\mathrm{H}$ was measured by elution from cellulose acetate strips. $\mathrm{Hb} \mathrm{F}$ was evaluated by alkaline denaturation according to the method described by Betke. ${ }^{7}$ Isopropanol test ${ }^{8}$ was performed. Heinz bodies were investigated by incubation with methyl violet and $\mathrm{Hb} \mathrm{H}$ was demonstrated by incubation with brilliant cresyl blue. ${ }^{9}$ Iron parameters were measured as previously described. ${ }^{10}$ DNA was extracted from whole blood using a 
phenol-chloroform method. ${ }^{11}$ Alpha thal deletion analysis was done using Gap$\mathrm{PCR}^{12}$ taking into account the ethnic origin and hematological data of the patients to detect the $-\alpha^{3.7},-\alpha^{4.2}$, — MED-I, _ SEA and $(\alpha)^{20,5}$ deletions. Nondeletional $\alpha$-thal Hph, $\mathrm{Nco}$ and $\mathrm{Hb}$ Constant Spring (CS) were detected with restriction enzymes $H p h$, $\mathrm{Nco}$ I and $\mathrm{Mse}$ I respectively. ${ }^{13,14}$ For point mutation analysis others than $\mathrm{Nco}, \mathrm{Hph}, \mathrm{Hb}$ $\mathrm{CS}$ and for structural alterations, amplification of the $\alpha_{2}$ and $\alpha_{1}$ globin genes was performed as previously described by using oligonucleotide primers (CyberSyn, Lenni, PA, USA). The amplified genes were subsequently purified and analyzed by direct sequencing.

\section{Results}

Of the 105 patients studied we were able to identify alpha globin genes mutations in 92 individuals (87.6\%): 88 patients with alpha thalassemia, three patients with structural alterations and one with both. In total, 13 individuals (12.4\%) had no identified $\alpha$-globin mutation.

Among the 89 individuals with $\alpha$-thal (88 $\alpha$-thal and one with $\alpha$-thal and $\alpha$ structural alteration), a total of $103 \alpha$-thal haplotypes were characterized, the most frequent among them was the $-\alpha^{3.7}$ mutation contributing to $73,8 \%$ of the studied alleles, followed by the $-(\alpha)^{20,5}(6.8 \%)$, - MED-I $(4.9 \%)$, - SEA $(3.9 \%), \alpha^{\mathrm{Hph}} \alpha(3.9 \%), \alpha^{\mathrm{Nco}} \alpha$ $(1.9 \%), \alpha^{\mathrm{CS}} \alpha(1.9 \%), \alpha^{\mathrm{IVSII}-142(\mathrm{G}>\mathrm{A})} \alpha(1.0 \%)$ and $-\alpha^{4.2}(1.0 \%)$ (Table 1). These determinants, along with the normal haplotype $(\alpha \alpha)$ were observed to interact in different genotypes as depicted in Table 2. The case with sickle cell trait was associated with $\alpha^{3.7}$ thal. Molecular characterization of the five cases of $\mathrm{Hb} \mathrm{H}$ revealed the following genotypes: $-(\alpha)^{20,5} /-\alpha^{3.7}$ (two cases), - ${ }^{\text {MED-I}} / \alpha^{\text {IVSII-142 }}$ ${ }^{(\mathrm{G}>\mathrm{A})} \alpha$ (one case), _ ${ }^{\mathrm{SEA} /} / \alpha^{3.7}$ (one case). In the remaining case with $\mathrm{Hb} \mathrm{H}$, in one allele the mutation $-\alpha^{3.7}$, which involves the loss of an alpha gene, was detected. Due to the fact that in the other allele not alpha genes amplified, a deletion encompassing both genes was inferred without being able to detect the extent of it (—del?/- $\alpha^{3.7}$ ). The case $\mathrm{Hb} \mathrm{H}$ like was characterized as $\alpha^{\mathrm{CS}} \alpha / \alpha^{\mathrm{CS}} \alpha$.

DNA sequencing of the $\alpha_{2}$ and $\alpha_{1}$ genes identified the $\alpha^{\text {IVSII-142(G>A) }} \alpha$ mutation and among the four individuals with $\alpha$ structural alterations the following hemoglobins: $\mathrm{Hb}$ Hasharon $(\alpha 247 \mathrm{Asp} \rightarrow$ His $)$, Hb Q-India $(\alpha 164 \mathrm{Asp} \rightarrow \mathrm{His}), \quad \mathrm{Hb} \quad$ Interlaken $(\alpha 115 \mathrm{Asp} \rightarrow \mathrm{His})$ and $\mathrm{Hb}$ Setif $(\alpha 247 \mathrm{Asp} \rightarrow$ Tyr $)$. The case with Hb Q-India was detected in association with $-\alpha^{3.7}$ thal and the one with $\mathrm{Hb}$ Interlaken in association with b-thal (CD 39).

\section{Discussion}

Ours results show that deletion $-\alpha^{3.7}$ is the most common in Rosario, where most individuals are of Mediterranean origin. The predominance of the $-\alpha^{3.7}$ deletion is consistent with the findings of several studies in the Mediterranean area and in Buenos Aires. ${ }^{15,16}$ This is the first mutation we try to identify in cases with low MCV $(<85 \mathrm{fL})$, low $\mathrm{MCH}(<27 \mathrm{dg})$, normal $\mathrm{HbA}_{2}$ and transferrin saturation of $>15 \%$, then we take into account the patient's ancestors and hematological data. Patients complete a form, which in addition to their personal data, indicate the mother's maiden name, the maternal grandmother, paternal grandmother and the origin of all of them to help us to know about their ancestors.

The three — SEA patients were of Chinese origin, the one with the — SEA $/ \alpha^{3.7}$ genotype of Taiwanese origin, the one with ${ }^{\mathrm{MED}} / \alpha^{\mathrm{IVSII}-142(\mathrm{G}>\mathrm{A})} \alpha$ was of Arab and Italian ancestry, ${ }^{17}$ the $\mathrm{Hb}$ Hasharon of Romanian and Polish descent. The remaining 86 patients had Mediterranean origin. These mutations had a heterogeneous distribution that varied according to individual ancestry.

We should consider the study of Mediterranean mutations because the current Argentinian population was formed by successive migratory waves. Amerindians already occupied Argentinian territory when the Spaniards arrived in 1500 and colonized the country. From the 16th to 19th centuries Africans were brought as slaves, with other migratory waves of Europeans occurring in the 19th and 20th centuries, mainly from Italy and Spain. ${ }^{3}$

We should also consider the study of alpha SEA thal because in our country we can identify three moments of influx of Chinese immigrants. The first was between 1914 and 1949, the second from 1978 and in the early years of the $80 \mathrm{~s}$ and the last flow of Chinese immigrants came from 1990 to about 1999. According to the Chinese Embassy in Argentina, it is estimated that today live in our country between 100,000 and 120,000 people of that origin,
Table 1. Spectrum of $\alpha$-gene defects.

\begin{tabular}{|c|c|c|}
\hline Alleles & $\mathrm{N}^{0}$ of mutations & Frequency (\%) \\
\hline$-\alpha^{3.7}$ & 76 & 73.8 \\
\hline$-(\boldsymbol{\alpha})^{20.5}$ & 7 & 6.8 \\
\hline$--_{\text {MED-I }}$ & 5 & 4.9 \\
\hline - - SEA & 4 & 3.9 \\
\hline$\alpha^{\mathrm{Hph}} \alpha$ & 4 & 3.9 \\
\hline$\alpha^{\mathrm{Nc0}} \alpha$ & 2 & 1.9 \\
\hline$\alpha^{c s} \alpha$ & 2 & 1.9 \\
\hline 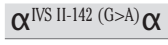 & 1 & 1.0 \\
\hline$-\alpha^{4.2}$ & 1 & 1.0 \\
\hline --del?* & 1 & 1.0 \\
\hline Total & 103 & 100 \\
\hline
\end{tabular}

*Mutation not found.
Table 2. Percentage of patients with alpha thalassemia, genotypes and phenotypes.

\begin{tabular}{|c|c|c|}
\hline Genotypes & $\begin{array}{c}\mathrm{N}^{\circ} \text { of patients }(\%) \\
\text { (Total=89) }\end{array}$ & Phenotypes \\
\hline$-\alpha^{3.7} / \alpha \alpha^{*}$ & $56(62.9)$ & $\alpha^{+}$ \\
\hline$-\alpha^{3.7 /}-\alpha^{3.7}$ & $7(7.9)$ & $\alpha^{0}$ \\
\hline$-(\alpha) 20.5 / \alpha \alpha$ & $5(5.6)$ & $\alpha^{0}$ \\
\hline$-{ }^{\mathrm{MED}} / \alpha \alpha$ & $4(4.5)$ & $\alpha^{0}$ \\
\hline$-{ }_{\mathrm{SEA}} / \alpha \alpha$ & $3(3.4)$ & $\alpha^{0}$ \\
\hline$-\alpha^{4.2 /} \alpha \alpha$ & $1(1.1)$ & $\alpha^{+}$ \\
\hline$\alpha^{\mathrm{Hph}} \alpha / \alpha \alpha$ & $2(2.2)$ & $\alpha^{+}$ \\
\hline$\alpha^{\mathrm{NCO}} \alpha / \alpha \alpha$ & $2(2.2)$ & $\alpha^{+}$ \\
\hline$-\alpha^{3.7} / \alpha^{\mathrm{Hph}} \alpha$ & $2(2.2)$ & $\alpha^{0}$ \\
\hline$-\alpha^{3.7} / \alpha \alpha^{\mathrm{HbQ} \text {-India }}$ & $1(1.1)$ & $\alpha^{0}$ \\
\hline$-(\alpha)^{20.5 /-} \alpha^{3.7}$ & $2(2.2)$ & $\mathrm{HbH}$ \\
\hline$--_{\text {SEA }} /-\alpha^{3.7}$ & $1(1.1)$ & $\mathrm{HbH}$ \\
\hline$-{ }^{\mathrm{MED}} / \alpha^{\text {IVS II-142 (G>A) }} \alpha$ & $1(1.1)$ & $\mathrm{HbH}$ \\
\hline$-\alpha^{3.7 /- \text { del? }}$ & $1(1.1)$ & $\mathrm{HbH}$ \\
\hline$\alpha^{\mathrm{cs}} \alpha / \alpha^{\mathrm{cs}} \alpha$ & $1(1.1)$ & $\mathrm{HbH}$ like \\
\hline
\end{tabular}


thus forming one of the largest recent immigrations. While most are installed in Buenos Aires, they are also found in cities such as Rosario, Mar del Plata and La Plata.

We have identified nine different mutations in the studied samples, six of which are $\alpha^{+}$defects $\left(-\alpha^{3.7},-\alpha^{4.2}, \alpha^{\text {Nco }}, \alpha^{\text {Hph }}, \alpha^{\text {IVSII- }}\right.$ $142(\mathrm{G} \rightarrow \mathrm{A})$ and $\mathrm{Hb} \mathrm{CS})$, the others are $\alpha^{0}$ defects (—MED, $-(\alpha)^{20,5}$ and $\left.-\mathrm{SEA}\right)$. According to our data, $68.5 \%(n=61)$ of patients with $\alpha$ - thal have a single $\alpha$-globin gene defect $(-\alpha / \alpha \alpha$ or $\left.\alpha^{t} \alpha / \alpha \alpha\right), 24.8 \%(n=22)$ have thalassemia trait $\left(-\alpha /-\alpha,-/ \alpha \alpha\right.$ or $\left.\alpha^{\mathrm{t}} \alpha /-\alpha\right)$ and $6.7 \%(\mathrm{n}=$ 6) have thalassemia intermedia $(-/-\alpha$, $/ \alpha^{t} \alpha$ or $\left.\alpha^{t} \alpha / \alpha^{t} \alpha\right)$.

The case with sickle cell trait and $-\alpha^{3.7}$ (MCV $80.3 \mathrm{fL}$ ), the one with Hb Hasharon (MCV $81.6 \mathrm{fL}$ ) and the one with $\mathrm{Hb}$ Setif (MCV 78.9 fL) had mild microcytic red blood cells. ${ }^{18}$ The patients with $\mathrm{Hb}$ Interlaken (MCV $62.4 \mathrm{fL}, \mathrm{MCH} 19.7$ pg) and $\mathrm{Hb}$ Q-India (MCV $71 \mathrm{fL}, \mathrm{MCH} 22 \mathrm{pg}$ ) had microcytic and hypochromic red blood cells because of the association with $\mathrm{b}(\mathrm{Hb}$ Interlaken) and $\alpha$-thalassemia ( $\mathrm{Hb} \mathrm{Q}$ India). ${ }^{19,20}$

Thirteen $(12,4 \%)$ of our 105 cases remained uncharacterized even after sequencing, and this maybe due to rare $\alpha$ globin gene deletions, gene duplications, mutations of the regulatory region and large $\alpha$-globin deletions, which would require further molecular studies. While we do not know how many of the cases that were undiagnosed are really alpha thalassemia, our service does not have the possibility to employ other techniques that probably would have allowed us to expand the number of diagnosed cases.

\section{Conclusions}

Of the 105 patients studied because of low MCV ( $<85 \mathrm{fL})$, low MCH $(<27 \mathrm{dg})$, normal $\mathrm{HbA}_{2}(\leq 3.5 \%)$ and transferrin saturation of $>15 \%$, we were able to identify $\alpha$ globin genes mutation in 92 individuals (87.6\%): 88 patients with $\alpha$-thal, three patients with structural alterations and one with both. In total, 13 individuals (12.4\%) had no identified $\alpha$-globin mutation. The most frequent mutation was the $-\alpha^{3.7}$ contributing to $73,8 \%$ of the studied alelles, followed by the $-(\alpha)^{20,5}(6.8 \%)$, - MED-I (4.9\%), — $(1.9 \%), \alpha^{\mathrm{CS}} \alpha(1.9 \%), \alpha^{\mathrm{IVSII}-142(\mathrm{G}>\mathrm{A})} \alpha(1.0 \%)$ and $-\alpha^{4.2}(1.0 \%)$. We diagnosed a case with sickle cell trait that was associated with $\alpha^{3.7}$ thal. Molecular characterization of five cases of $\mathrm{Hb} \mathrm{H}$ revealed: $-(\alpha)^{20,5} /-\alpha^{3.7}$ (two cases), — ${ }^{\mathrm{MED}-\mathrm{I}} / \alpha^{\mathrm{IVS}} \mathrm{II}-142(\mathrm{G}>\mathrm{A}) \alpha$ (one case), $\mathrm{SEA} /-\alpha^{3.7}$ (one case). In the remaining case with $\mathrm{Hb} \mathrm{H}$, in one allele the mutation $-\alpha^{3.7}$ was detected; in the other allele we were not able to identified the extent of the deletion (—del? $/-\alpha^{3.7}$ ). One case $\mathrm{Hb} \mathrm{H}$ like was characterized as $\alpha^{\mathrm{CS}} \alpha / \alpha^{\mathrm{CS}} \alpha$. DNA sequencing of the $\alpha_{2}$ and $\alpha_{1}$ genes identified the $\alpha^{\text {IVS II-142 }}$ ${ }^{(\mathrm{G}>\mathrm{A})} \alpha$ mutation and four $\alpha$ structural alterations: $\mathrm{Hb}$ Hasharon, $\mathrm{Hb}$ Q-India, $\mathrm{Hb}$ Interlaken and $\mathrm{Hb}$ Setif. The case with $\mathrm{Hb}$ Q-India was detected in association with $\alpha^{3.7}$ thal and the one with $\mathrm{Hb}$ Interlaken in association with $\beta$-thal (CD 39).

Our knowledge about $\alpha$ structural alteration and our findings on the prevalence of $\alpha$-thal mutations will provide a valuable basis for carrier screening, genetic counseling and prenatal diagnosis and may be we will be able to help prevent the passing on of these mutations to future generations.

\section{References}

1. Piel FB, Weatherall DJ. The alpha-thalassemias. N Engl J Med 2014;371: 1908-16.

2. Williams TN, Weatherall DJ. World distribution, population genetics, and health burden of the hemoglobinopathies. Cold Spring Harb Perspect Med 2012;2:a011692.

3. Salzano FM, BortoliniMC. The evolution and genetics of Latin American populations. Cambridge: Cambridge University Press; 2002. pp 512.

4. Galanello R, Cao A. Alpha-thalassemia. Genet Med 2011;13:83-8.

5. Harteveld CL, Higgs DR. Alpha-thalassaemia. Orphanet J Rare Dis 2010;5:13.

6. Bragós IM, Noguera NI, Morisoli L, et al. Most frequent mutations in $\beta$-thalassemia in a population in Rosario, Argentina. Haematologica 2000;85: Bragós, 1001-2.

7. Efremov GD, Huisman THF. Diagnótico de laboratorio de hemoglobinopatías en Hemoglobinas anormales. In: Weatherall DJ, ed. Clínica Hematológica 2/2. Barcelona: Salvat; 1976. pp 319-320, 322-323.

8. Carrell RW, Kay R. A simple method for the detection of unstable haemoglobins. Br J Haematol 1972;23:615-9.

9. Dacie JV, Lewis SM. Practical haematology. 8th edn. Edinburgh: Churchill Livingstone; 1995.

10. International Committee for Standardization in Haematology (ICSH). The measurement of total and saturated iron binding capacity in serum. Br J Haematol 1978b;38:281-7.

11. Noguera NI, Tallano C, Bragós IM, et al. A modified salting-out method for DNA isolation from newborn cord blood nucleated cells. J Clin Lab Analysis 2000;14:280-3.

12. Oron-Karni V, Filon D, Oppenheim A, et al. Rapid detection of common Mediterranean $\alpha$-globin deletions/ rearrangements using PCR. Am J Hematol 1998;58:306-10.

13. Ayala S, Colomer D, Aymerich M, et al. Nondeletional a-thalassemia: first description of $\alpha \mathrm{HPh} \alpha$ and $\alpha \mathrm{Nco} \alpha$ mutations in a Spanish population. Am J Hematol 1996;52:144-9.

14. Noguera NI, González FA, Ropero P, et al. Homozygous Constant Spring: the first case described in the west. Haematologica 2000;85:667-9.

15. Villegas A, Ropero P, González FA, et al. The thalassemia syndromes: molecular characterization in the Spanish population. Hemoglobin 2001;25:273-83.

16. Scheps KG, Francipane L, Nash A, et al. Bases moleculares de alfa-talasemia en la Argentina. Medicina (Buenos Aires) 2015;75:81-6.

17. Noguera NI, Gonzalez FA, Davoli RA, et al. A novel splice acceptor site mutation of the alpha2-globin gene causing alpha thalassemia. Hemoglobin 2001,25:311-5.

18. Steinberg MH, Adams JG 3rd, Dreiling BJ. Alpha thalassaemia in adults with sickle-cell trait. Br J Haematol 1975; 30:31-7.

19. Ojeda MJ, Perez SM, Calvo KL, et al. Hemoglobin Interlaken in combination with beta thalassemia trait. Thalassemia Reports 2013;3:e3.

20. Perez SM, Noguera NI, Acosta IL, et al. Compound heterozygosity of $\mathrm{Hb} \mathrm{Q}$ India $[\alpha 64$ (E13) $\mathrm{ASP} \rightarrow \mathrm{HIS}]$ and $-\alpha^{3.7}$ thalassemia. First report from Argentina. Rev Cubana Hematol Inmunol Hemoter 2010;26:236-40. 